\title{
Social Exclusion and Anti-Immigration Attitudes in Europe: The mediating role of Interpersonal Trust
}

\author{
Valerio Pellegrini ${ }^{1}$ (D) . Valeria De Cristofaro ${ }^{1} \cdot$ Marco Salvati $^{1} \cdot$ Mauro Giacomantonio $^{1}$. \\ Luigi Leone ${ }^{1}$
}

Accepted: 7 January 2021 / Published online: 31 January 2021

(c) The Author(s) 2021

\begin{abstract}
Managing immigration is a challenge at the political, economic, and social levels. Clarifying the social psychological antecedents behind the onset of negative attitudes towards immigrants might help overcome this challenge. The present study investigates the relationships between people's experience of social exclusion, feelings of generalized interpersonal trust, and anti-immigrant attitudes across 23 European countries. We used data from the European Social Survey 8 (2016), employing a representative sample of the European population. A 1-1-1 multilevel mediation model showed that: (a) the higher the experience of social exclusion, the lower the generalized trust towards others; (b) the experience of social exclusion related positively and directly with anti-immigration attitudes; and (c) generalized interpersonal trust mediated the relationship between experienced social exclusion and anti-immigrant attitudes so that the experience of being socially excluded reduced feelings of generalized interpersonal trust that, in turn, promoted hostile attitudes towards immigrants. Taken together, these results create a platform for future research on the emergence of negative attitudes towards immigrants and factors that might facilitate the development of a climate of integration and acceptance.
\end{abstract}

Keywords Social exclusion · Interpersonal trust $\cdot$ Anti-immigration attitudes $\cdot$ Multilevel mediation $\cdot$ Mixed models

\section{Introduction}

The migratory flows towards Europe are constant, and their management is one of the most important challenges for the transformation of Western and European societies. The growing climate of hostility towards immigrants witnessed across Europe (e.g. Italy, Hungary, Poland, and the Russian Federation) shows that much remains to be done to manage this phenomenon adequately. An accurate understanding of the social psychological dynamics linked to immigration could shed light on the importance of specific factors.

Valerio Pellegrini

valerio.pellegrini@uniroma1.it

1 Department of Social and Developmental Psychology, Faculty of Medicine and Psychology, Sapienza University, Rome, Italy 
The increase in anti-immigration attitudes has often been traced back to economic factors. Some studies showed that natives fear that the presence of immigrants in the host country may affect the labour market by depressing wages (Mayda 2006; Scheve and Slaughter 2001), lead to a heavier tax burden, and increase pressure on welfare and social services (Facchini and Mayda 2009; Hanson et al. Slaughter 2007). Other studies related anti-immigration attitudes with non-economic factors; for example, negative attitudes towards immigrants have been associated with social categorization processes (Tajfel and Turner 1986), which lead people to evaluate others on the basis of their ethnic origin (Brown 2011) and produce the emergence of prejudices and stereotypes (Roets and Van Hiel 2011). Scholars of intergroup dynamics have also tried to integrate the abovementioned perspectives under the theoretical strand of the group size hypothesis (e.g. Quillian 1995; Rink et al. 2008; Wilkes et al. 2007). However, as shown by a recent meta-analysis by Pottie-Sherman and Wilkes (2017), this hypothesis has received only partial support.

It appears that a further look at the psychological antecedents underpinning hostile sentiments towards immigration is advisable. In the present article, we focus on social exclusion and interpersonal trust as determining factors of anti-immigration attitudes. Specifically, we investigate whether natives' experience of social exclusion may shape antiimmigrant attitudes not only directly but also indirectly through feelings of generalized interpersonal trust.

Previous research provided evidence for the role of social exclusion in the context of immigration (see Gradstein and Schiff 2006). However, the authors focused on social exclusion in terms of the different integration levels of an immigrant in the new country-in other words, they considered the exclusion experienced by immigrants as a case study. At the same time, other studies (e.g. Twenge et al. 2007) focused on social exclusion as a predictor of interpersonal trust, trying to connect their interplay to anti-social outcomes. Nevertheless, they did not find any support for the idea that interpersonal trust mediates the effects of social exclusion on such outcomes. Moreover, the role of trust in shaping negative attitudes towards people from different ethnic groups has also been examined (e.g. Chang and Kang 2018; Herreros and Criado 2009; Rustenbach 2010). The authors of these studies found that both abstract (i.e. generalized trust) and specific levels of interpersonal trust (i.e. towards foreigners) are central for explaining negative attitudes towards immigrants. However, none of them examined the potential connections between the concepts of social exclusion and interpersonal trust in relation to the emergence of anti-immigrant sentiments. By focusing on the joint role of experienced social exclusion and interpersonal trust in Europe, the present study aims to provide new insight on the emergence of antiimmigration attitudes. We investigated the proposed relationships across 23 European countries by implementing 1-1-1 multilevel mediation analysis.

\section{Social Exclusion and Interpersonal Trust}

Social exclusion is a complex and multidimensional process. It may imply a lack of resources, rights, goods, and services. At the same time, it may relate to the inability to participate in normal social relationships and activities. Social exclusion may therefore involve different domains of people's lives in a society, in the economic, social, cultural, or political spheres, and affect both the quality of their life and the equity and cohesion of society (Levitas et al. 2007; Silver 1994, 1995). Burchardt (2000) proposed the following definition of social exclusion: "An individual is socially excluded if he or she does not 
participate to a reasonable degree over time in certain activities of his or her society, and (a) this is for reasons beyond his or her control, and (b) he or she would like to participate" (p. 388).

Research in social psychology has investigated the effects of social exclusion, sometimes producing contrasting results. For instance, Williams and Sommer (1997) and Maner et al. (2007) have highlighted that excluded people were motivated to break through the unpleasant state of exclusion and thus may wish to create new social bonds. The authors found that excluded individuals were more interested in interacting with new potential partners and evaluating unknown people in a positive and friendly fashion. As a consequence, excluded people should be ready and willing to cooperate; however, this was the case only in situations when the person with whom they had to interact undertook and maintained a cooperative position (Twenge et al. 2007). Instead, other studies have shown strikingly different consequences or correlates of exclusion, pointing to antagonistic and uncooperative outcomes. It has been found that children who were rejected by their peers acted in a less prosocial way (e.g. Gest et al. 2001), that social exclusion led to aggressive behaviour (e.g. Twenge et al. 2001), self-harm (Twenge et al. 2002), to impulsive and uncontrolled acts (Baumeister et al. 2005) and to feelings of obstructing and non-collaborative behaviour (Twenge et al. 2007). Social exclusion thus may induce individuals to become introverted, closed, uncooperative, and antisocial.

Such apparently contrasting consequences nonetheless shed light on a fundamental aspect that characterizes people who are victims of social exclusion. As suggested by Twenge and colleagues (2007), socially excluded people, rather than providing an a priori negative evaluation, adopt an attitude that can be defined in terms of suspicion and lack of trust in other people. In fact, social exclusion can be experienced as a betrayal of trust by one's own reference group, social system, or a significant other, because a tacit expectation of reciprocity and belonging is not fulfilled. This may concern the above-mentioned domains that constitute the individual existence. Lack of the economic resources necessary to satisfy one's own needs and those of one's family, poor health that does not allow carrying out social or work activities, and the inability to participate actively in the political and social life of one's own country represent some of the deprivations that face an individual in a condition of social exclusion. In constructing their social life, individuals make efforts to satisfy their overwhelming need for belonging (Baumeister and Leary 1995). When an individual experiences deprivation, the individual's sacrifices and the efforts he or she expended to create the desired social bonds are revealed as ineffectual, because they have not led to any of the rewards associated with belonging and inclusion-so it appears that one's trust in other people has been misplaced. Consequently, individuals may infer that it would be better to proceed with caution and suspicion in any subsequent social interaction.

Suspicion about future social interactions in response to experiencing exclusion can become a chronic state of mind that influences individual judgements and attitudes towards other people. This mental state is represented by the trust a person feels about other people or groups, and it is known as interpersonal trust (Rotter 1980). It represents the degree to which an individual is confident that other people will behave in a fair, ethical, and predictable manner.

Interpersonal trust has mainly been investigated according to two theoretical strands: the normative (Uslaner 2002) and the rational (Hardin 2002) approaches. The normative approach assumes that trust is guided in an ascribed and normative way; that is, it depends on the widespread belief within a community that people share (or do not share) the same moral values and normative standards. These values and standards regulate individual conduct and allow people to have expectations about fair and honest behaviour (Fukuyama 
1995; Uslaner 2002). The rational approach presupposes that interpersonal trust is motivated in a rational way by interconnected interests that bind individuals. People form expectations about the behaviour of others because, to live in harmony within a society, it is necessary to meet and respect common interests (Hardin 2002). When other peoples' behaviours disregard such interconnected interests, trust declines.

The normative approach provides a general view of human nature, indicating that trust does not depend so much on personal experiences of assumptions that others are trustworthy, but rather on general beliefs dictated by ascribed aspects. In contrast, the rational approach emphasizes the acquired rather than the ascribed aspects, indicating that interpersonal trust depends on the events experienced by individuals during their social life (Uslaner 2008). Individuals learn the specific meanings of cultural and personal traits about trustworthiness through their direct and indirect experiences, and their decisions about whether to trust others are dictated by the outcomes of such experiences (Chang and Kang 2018). If trust can be affected by direct experiences of social interaction, social exclusion can represent a relevant factor in increasing distrustful attitudes. A person who, in everyday life, does not have the opportunity to participate in collective activities or to meet friends or colleagues can hardly infer that others can be trusted. Similarly, a person who does not have access to indispensable resources to satisfy his or her needs and who cannot rely on a social and relational system capable of compensating for these shortcomings may perceive the ascribed moral and normative principles, upon which trust is based, as violated. As such, this person may tend to believe that people who manage this system and who are part of his or her relational network are untrustworthy. These evaluations may become generalized to a more abstract level and crystallized into a widespread view of people in general. The consolidated and generalized belief of untrustworthiness towards people felt by natives of a hosting country can represent a powerful antecedent of antiimmigrant attitudes (Rustenbach 2010).

\section{Interpersonal Trust and Anti-Immigration Attitudes}

Comparing an array of possible explanations for the rise of anti-immigration attitudes, Rustenbach (2010) found that anti-immigration attitudes in Europe were largely driven by interpersonal trust, educational level, and political factors. The explanations tightly linked to economic factors and those related to the sheer number of immigrants, often considered as the key drivers of anti-immigration attitudes, turned out to be relatively weakly linked to attitudes towards immigrants. Rather, Rustenbach (2010) found that interpersonal trust was the strongest predictor of anti-immigration attitudes. She framed this within what she defines as societal integration, that is, the possibility for immigrants to be able to integrate with the host society and culture. According to this explanation, people are more likely to adopt anti-immigrant attitudes when they cannot relate to immigrants because of a cultural distance. Individuals from different ethnic groups are more likely to come into conflict with each other because their identities are shaped within communities based on different cultural roots. Negative attitudes towards immigrants may arise when natives feel they lack shared factors on which to establish trust. Conversely, when a certain cultural affinity is perceived, there might be a greater probability that natives develop more favourable attitudes towards immigration. Immigrants embody several features that natives may view with uneasiness, such as different worldviews, moral standards, and religious beliefs. Natives may adopt anti-immigration attitudes because they are afraid that features 
associated with immigration might adversely affect their lives, values, and habits. Individuals with low levels of interpersonal trust may believe that cultural differences are insuperable. Thus, they may be less willing to overcome the unpredictability associated with such differences and refuse to establish relationships with immigrants (Rustenbach 2010). Furthermore, living in a context in which interpersonal trust is scarce-perhaps because of social exclusion-may shape a diffuse hostile climate in terms of acceptance of immigrants, where they are generally perceived in a more negative way, consolidating individual prejudicial perceptions.

Cultural diversity may therefore foster an unsettling feeling of unpredictability among natives. If previous experiences of social interaction have repeatedly produced negative outcomes, this uncertainty could be resolved by veering towards a negative anticipation of such consequences. In turn, this anticipation may favour the adoption of negative attitudes towards the eventuality of having to host immigrants. In other words, the perceived lack of common factors on which trust might be built, amplified by the generalized belief of people as unreliable deriving from experiences of exclusion, might favour the arise of antiimmigrant sentiments.

\section{Research Overview and Hypotheses}

In light of these arguments, the present study examined the association between social exclusion, interpersonal trust, and anti-immigration attitudes. We expected that social exclusion could be positively associated with the emergence of anti-immigration attitudes and negatively related with interpersonal trust. We also expected that social exclusion could be indirectly associated with anti-immigration attitudes through interpersonal trust. Importantly, these associations were expected to be consistent across representative samples of the population of 23 European countries.

The distinction between the normative and the rational approach to the study of trust offers a relevant theoretical cue to explain the reasoning behind our study and the relative research hypotheses. We aimed to integrate the different approaches and consider trust as an outcome of the extent of social exclusion experienced by individuals. We proposed that the experience of social exclusion would induce a widespread feeling of generalized distrust towards individuals, favouring the emergence of negative attitudes towards immigrants.

As noted above, social exclusion can be experienced in different life domains. For instance, an individual may find participation in social and political life hindered due to health problems. At the same time, the same individual may not receive help from friends and family to overcome such impediments: in other words, he or she may not have adequate social support. Plausibly, this individual may feel not satisfied with his or her life in general. The same process could similarly affect other domains (e.g. economic), thus placing a person in a state of social exclusion. As Burchardt (2000) has pointed out, deprivations experienced by individuals are often attributed to other people who are part of a given domain, sphere, or social system. As a consequence, these deprivations shape the individuals' feelings of trust towards other people. The spread of deprivation episodes in several life domains, and the consequent state of permanent isolation, can lead individuals to consider this type of condition as not restricted to their directly experienced reality, and it may produce a general sense of disappointment and frustration towards most people, establishing an association between the experience of social exclusion and low interpersonal trust. 
In turn, such generalized distrust might favour the emergence of negative attitudes towards certain social targets, in particular when they are easily identifiable because of apparent differences in ethnicity, culture, habits, and values. Immigrants could easily embody one of these targets.

Empirically, we anticipated that social exclusion could be a predictor of lack of trust among people, which in turn could lead people to express negative attitudes towards immigrants and immigration. Specifically: (a) a high level of social exclusion could negatively relate to the level of generalized interpersonal trust; (b) social exclusion should also relate to increases in anti-immigration attitudes; and (c) this latter direct association could be mediated by interpersonal trust.

We were also interested in exploring whether these paths varied across European nations. We therefore decided to implement a multilevel mediation model when testing our hypotheses. We assumed that the predicted mediation could have specific nuances depending on the participants' country of origin. We nevertheless expected that the associations and the mediation pattern detailed above would remain significant, on average, across countries. Multilevel modelling allowed us to test our hypotheses with accuracy and to provide greater generalizability and reliability for the results.

\section{Method}

\subsection{Data and Participants}

We examined data from a representative sample of the European population using the European Social Survey 8 (ESS Round 8 2016). The ESS represents a scientific social endeavour to map the attitudes, beliefs, and behaviour patterns of various populations in Europe. It was established to obtain a new time series of scientific data of high methodological rigour. It is therefore considered a reliable source from which to draw for the investigation of cross-national attitudes and the monitoring of their changes over time in Europe. The ESS adheres to high methodological and translation standards, obtaining an optimal comparability of the data collected in all countries (European Social Survey 2017).

ESS sampling is based on the design and implementation of viable and equivalent sampling plans in all participating countries. Thus, the survey consists of representative samples of all people aged 15 and over (with no upper age limit), residing in private homes in each country, regardless of their nationality, citizenship, or language. Individuals are selected with rigorous random probability methods at each ESS round. All countries involved in the survey provide a sample size of at least 1,500 people, or 800 in countries with populations of less than 2 million. In each ESS round, teams of multinational researchers are selected to help in the design of the questionnaire, and new data are collected compared to previous rounds (European Social Survey 2017).

We decided to use ESS data to increase confidence about the generalizability of emerged results to the population of the European Community. ESS Round 8 data were collected in 2016 and consisted of 44,387 individuals $(23,351$ females, Mage $=49.14$, SDage $=18.61)$ from 23 countries of the European Union. Among the sample, the education level was distributed as follows: $8.7 \%$ had less than a lower secondary school diploma, $16.7 \%$ a lower secondary school diploma, $35.9 \%$ a high school diploma, and $14.2 \%$ an advanced vocational qualification, while the remaining $24.4 \%$ had a degree or a higher-level qualification. Regarding participants' work condition, $52.3 \%$ were employed, $7.8 \%$ were students, 
$5.1 \%$ were unemployed, $24.8 \%$ were retired, $6.2 \%$ worked at home, and $2.6 \%$ were unable to work due to illness or disability. Important for the study purpose, $89.4 \%$ of participants were born in the country for which they participated in the survey, while the remaining $10.6 \%$ were born in a different country. For a detailed description of the sample's demographics for the 23 countries involved in ESS Round 8, see Table 1.

\section{Measure}

To provide greater clarity and ease interpretation of the results, all of the following measures have been rescaled on a range of values between 0 and 1 (e.g. Arikan and Sekercioglu 2019). We decided to rescale the variables, rather than standardize them, because in a multilevel mediation model it is essential not to lose the information about the average score of predictors associated with each level-2 unit.

\section{Social Exclusion}

As previously anticipated, social exclusion represents a multidimensional construct that involves different aspects of individual existence. Although it is not straightforward to find an operationalization capable of covering these different aspects, the Bristol Social Exclusion Matrix (B-SEM; Levitas et al. 2007) and Social Exclusion Monitor (SEM; Scutella et al. 2009) have summarized social exclusion in three main domains: resources, participation, and quality of life. These domains are composed, respectively, of different indicators such as economic and material resources (e.g. income), social support, social and political participation, health and well-being, and life satisfaction. Therefore, following the indications provided by B-SEM and SEM, we endeavoured to put together a series of indicators among those available in the ESS that were able to cover as broadly as possible the three main domains that constitute the social exclusion construct. Furthermore, the items were suggested by the ESS as indicators of social exclusion. Thus, for the resources dimension, three items (i.e. "How you feel about your household's income nowadays?"; "During the next 12 months how likely is it that there will be some periods when you don't have enough money to cover your household necessities?"; "Please tell me which letter describes your household's total income, after tax and compulsory deductions, from all sources?") have been included. The first two items were answered on 4-point Likert scale where $1=$ Living comfortably on present income and $4=$ Finding it very difficult on present income, and $1=$ Not at all likely and $4=$ Very likely, respectively. The third item asked participants to place their income between the lowest (1st) and highest (10th) deciles. For the participation dimension, we used five items. Specifically, three items concerned participants' social participation (i.e. "How often do you meet socially with friends, relatives or work colleagues?"; "How many people, if any, are there with whom you can discuss intimate and personal matters?"; "Compared to other people of your age, how often would you say you take part in social activities?") and two items concerned participants' political participation (i.e. "How able do you think you are to take an active role in a group involved with political issues?"; "And how confident are you in your own ability to participate in politics?"). These items were rated on 7-point and 5-point Likert scales respectively, ranging from a low to high participation score. Lastly, four items were used as indicators of the quality of life dimension (i.e. "All things considered, how satisfied are you with your life 


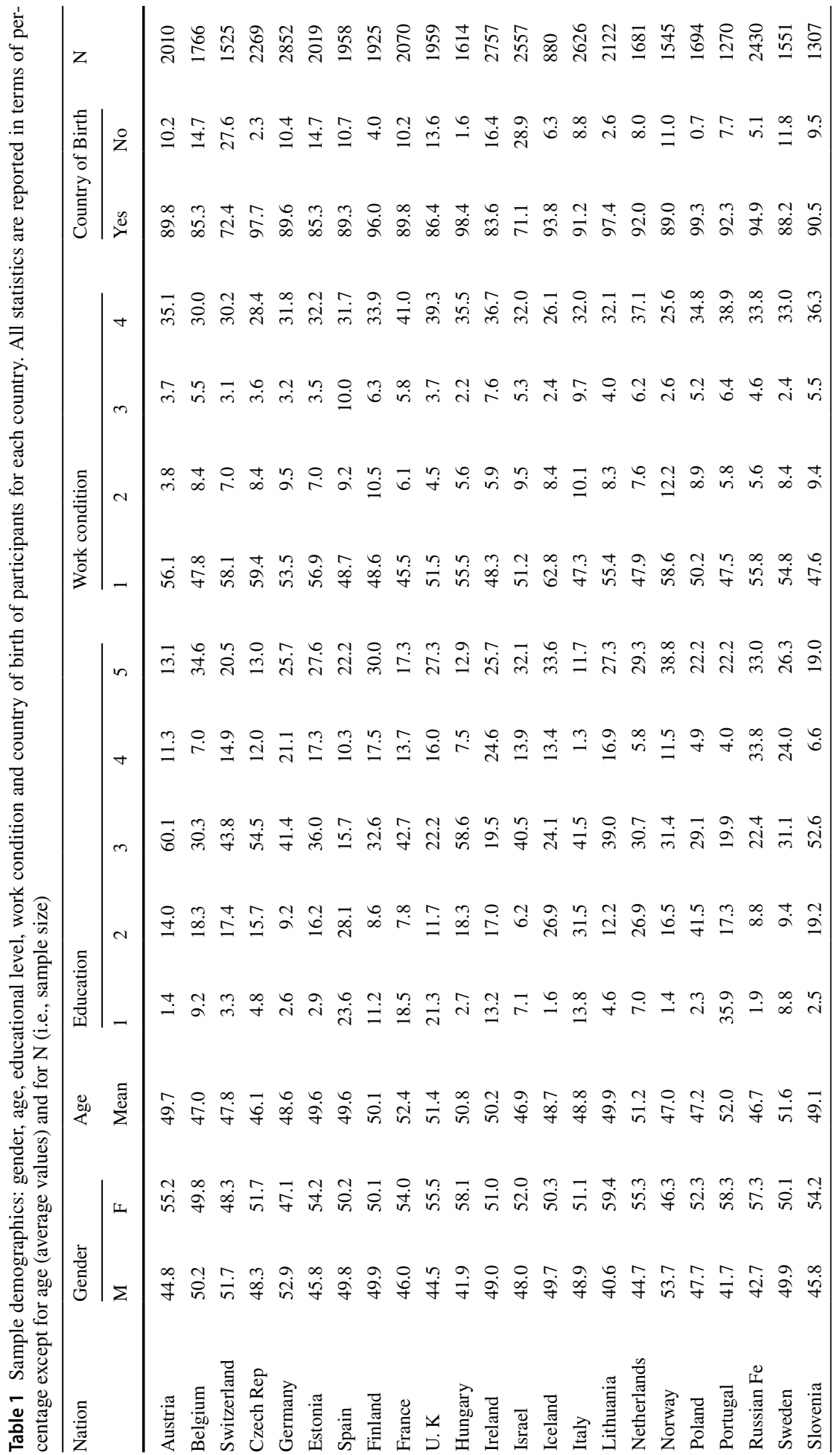




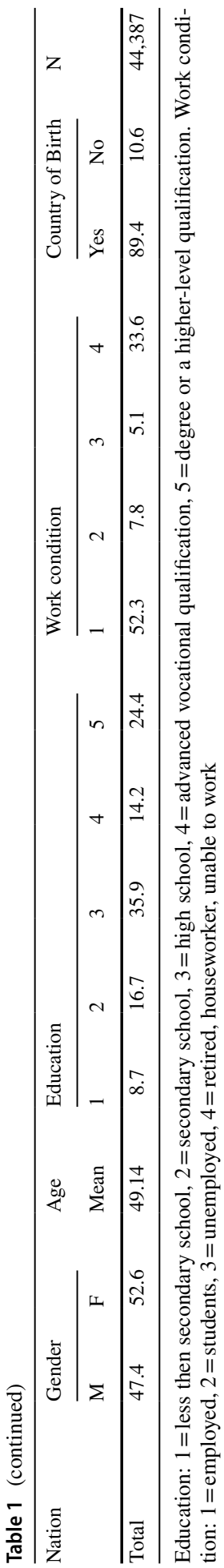


as a whole nowadays?"; “Taking all things together, how happy would you say you are?"; "How is your health in general? Would you say it is ..."; "Are you hampered in your daily activities in any way by any longstanding illness, or disability, infirmity or mental health problem? If yes, is that a lot or to some extent?"). The first two items were answered on an 11-point Likert scale ranging from 0 (Extremely unsatisfied/unhappy) to 10 (Extremely satisfied/happy). The other two items were rated on 5-point and 3-point Likert scales, respectively, ranging from high to low levels of health/well-being. To ensure that high scores corresponded to high experience of social exclusion, the values of interested items were reversed. Once the items were reversed and rescaled, we computed the overall score, averaging the response provided for each one $(M=0.42 ; S D=0.14)$. The Cronbach's alpha for the items composing the social exclusion scale $(\alpha=0.78)$, as well as each dimension of resources $(\alpha=0.70)$, participation $(\alpha=0.64)$, and quality of life $(\alpha=0.71)$ was satisfactory.

To test the measure's factorial structure, we conducted confirmatory factorial analysis (CFA). We implemented a second order CFA model where the indicators listed above reflected the three dimensions of resources, participation, and quality of life. In turn, these dimensions constituted a further overarching factor (i.e. social exclusion). CFA revealed that the model adhered to the empirical data $\left(\chi^{2}[47]=2660.99, p<0.001 ; \mathrm{CFI}=0.97\right.$; $\mathrm{TLI}=0.96$; $\mathrm{SRMR}=0.031$; RMSEA $=0.041,90 \% C I=0.040,043)$. First order factor loadings ranged from 0.41 to 0.92 , whereas those of second order were equal to $0.73,0.77$, and 0.93. All of them achieved statistical significance.

\section{Interpersonal Trust}

To investigate the extent to which participants felt confidence in other people, we used three items labelled as interpersonal trust in the ESS. The items (i.e. "Generally speaking, would you say that most people can be trusted, or that you can't be too careful in dealing with people?"; "Do you think that most people would try to take advantage of you if they have the chance, or would they be fair?"; "Would you say that most of the time people try to be helpful or that they are mostly looking out for themselves?") addressed participants' generalized view of people as untrustworthy, and they are assimilable to some of the items proposed in Rotter's $(1971,1980)$ measure of trust. These items were answered using an 11-point Likert scale ranging from 0 (low trust) to 10 (high trust). We rescaled items in a range of values between 0 and 1 and averaged the scores across items $(M=0.54$; $S D=0.19)$ such that lower scores reflected lower interpersonal trust. Reliability was satisfactory $(\alpha=0.76)$.

Even for this measure, we tested factorial structure with CFA. Because only three items about trust were available, we tested an identified model. The analysis showed that the three indicators significantly loaded on the latent dimension of interpersonal trust, highlighting factor loadings equal to $0.75,0.74$, and 0.67 .

Anti-Immigration Attitudes were measured by six items. Three of the items (i.e. "To what extent do you think [country] should allow people of the same race or ethnic group as most [country] people to come and live here?"; "How about people of a different race or ethnic group from most [country] people?"; "How about people from the poorer countries outside Europe?") focused on the extent to which the government should allow people from foreign countries to arrive in the host nation. Participants expressed their opinion on a 4-point Likert scale ranging from $1=$ allow many to $4=$ allow none. The remaining three items (i.e. "Would you say it is generally bad or good for [country]'s economy that people come to live 
here from other countries?"; "Would you say that [country]'s cultural life is generally undermined or enriched by people coming to live here from other countries?"; "Is [country] made a worse or a better place to live by people coming to live here from other countries?") focused on the perception of immigrants as a threat, rather than as an opportunity for the host country. The scale of these items ranged from 0 (threat) to 10 (enrichment), and we therefore reversed them such that high scores reflected a perceived threat. The overall anti-immigration attitude score was obtained by rescaling the values between 0 and 1 and then averaging the answers to all six items $(M=0.48 ; S D=0.22 ; \alpha=0.89)$.

This measure thus investigated anti-immigration attitudes through two dimensions: one relating to a general view of immigration as something negative or positive for the host country and another linked to a negative or positive stance about the arrival of new immigrants in the host country. Second order CFA revealed that the two-dimensional model fitted satisfactorily with the empirical data $\left(\chi^{2}[7]=392.11, p<0.001 ; \mathrm{CFI}=0.99\right.$; TLI $=0.99 ; \mathrm{SRMR}=0.013$; $\mathrm{RMSEA}=0.037,90 \% C I=0.035,040)$. The first order factor loadings ranged from 0.73 to 92 , whereas those of the second order were equal to 0.82 and 0.87 . All of the loadings were significant.

\section{Covariates}

To test the robustness of the results, we inserted seven covariates into the analysis model. Scores were rescaled to values between 0 and 1 . Thus, we partialized the effects of predictor and mediator for participants' age, educational level, gender, political orientation, country of birth, belonging to a minority ethnic group, and the number of people living regularly as household members. Political orientation $(M=0.52 ; S D=0.22)$ was measured by an item (i.e. 'In politics people sometimes talk of 'left' and 'right'. Using this card, where would you place yourself on this scale, where 0 means the left and 10means the right?"). This item was easily identifiable as the classical "left-right" dimension of political orientation and was included because it is a proved relevant factor affecting the rise of anti-immigration attitudes (e.g. De Cristofaro et al. 2019) and the sentiment of distrust (e.g. Kutiyski et al. 2019). Educational level was assessed through the International Standard Classification of Education (ISCED). We focused on age, gender, and educational level because they represent factors capable of intervening in the relationships between social exclusion, interpersonal trust, and anti-immigration attitudes (see Cavaillé and Marshall 2019; Eurostat 2018, 2019; Ponce 2017; Rustenbach 2010; Ward et al. 2016). Country of birth and belonging to a minority ethnic group were assessed with the following items: "Were you born in [country]?" and "Do you belong to a minority ethnic group in [country]?" respectively, to which participants answered "Yes or "No". They were included as control for the migrant background of the respondent. Finally, the item "Including yourself, how many people-including children-live here regularly as members of this household?" was considered because it was likely to engrave the levels of experienced social exclusion and consequently its effect on anti-immigration attitudes and interpersonal trust. 


\section{Analytic Strategy and Preliminary Analyses}

In the present paper, we proposed our hypothesis as a 1-1-1 multilevel mediation model. Thus, we tested the expected (a) negative relationship between social exclusion and interpersonal trust, (b) negative relationship between interpersonal trust and anti-immigration attitudes, and (c) the positive association of social exclusion and anti-immigration attitudes. Contextually, we also tested the indirect association of exclusion with negative attitudes towards immigrants through interpersonal trust. All of the above-mentioned relationships were simultaneously estimated in a unique model that revealed the average within-nation direct and indirect effects, considering the random variation of parameters across the 23 European countries involved in the study.

Multilevel mediation analysis considers the nested structure of data. The hierarchical order is conventionally indicated through a numerical system that describes the measurement level of each variable (Bauer et al. 2006). In circumstances where the researcher is interested in the effects of a level-2 variable (e.g. the economic policy of a nation) on a variable measured at level 1 (e.g. the well-being of citizens) through a variable measured at level 2 or 1 (e.g. the GDP of a nation or citizen income, respectively) it is conventional to talk about $2-2-1$ or $2-1-1$ mediation. In these cases, the data hierarchy is of direct importance, because the researcher is interested in testing the differences between clusters of the effect of X (measured at level 2) on M (measured at level 2 or level 1) on Y (measured at level 1). When, as in our case, one is interested in a mediation analysis where all the variables are measured at level 1, and the dependence of the data on the nested structure must be taken into account, reference is made to a 1-1-1 multilevel mediation (Rockwood 2017). In this circumstance, the researchers are interested in testing the average indirect effect of $\mathrm{X}$ (i.e. social exclusion) on Y (i.e. anti-immigration attitudes) through $\mathrm{M}$ (i.e. interpersonal trust) within each level-2 unit (i.e. 23 European countries). The strength of a 1-1-1 multilevel mediation model lies in the fact that in the estimation of the indirect effect the random variability of the parameters is also taken into account (Rockwood 2017). This kind of analysis allowed us to estimate the predicted mediating path within nations, considering simultaneously the random variability across nations of the paths of interest.

Before proceeding with multilevel analysis, it is conventional to run some preliminary analyses to ascertain if this kind of analysis is necessary on the basis of the data structure. Usually, researchers may assess the amount of variance of the dependent variable that is explained by the nested nature of the data, as well as whether the number of clusters is adequate for an accurate test of the research hypotheses. Thus, as a preliminary analysis to ascertain if a linear mixed model was necessary, we computed the intraclass correlation coefficient (ICC) for the dependent variable, to gauge the amount of variability due to the different countries. We thus ran the analysis on the null model to test the variability of the anti-immigration attitudes across the level-2 factor (i.e. the 23 European nations). The ICC was equal to 0.19 , indicating that the $19 \%$ of anti-immigration attitudes variance was explained by the clusters' structure. The between-variance estimate of anti-immigration attitudes was 0.0098 ( $S E=0.0029)$, with a significant Wald test $(Z=3.38, p<0.001$, $95 \% C I=0.0055,0.0175)$. As further evidence to support the need to consider the nested structure of the data, we conducted a likelihood ratio test (Hayes 2006) comparing two null models (one with the intercept as a random effect and the other, without the intercept, as a random effect), which came out decisively significant $\left(\chi^{2}[1]=8369.547 ; p<0.001\right)$. The model which considered the random intercept of anti-immigration attitudes was therefore significantly more informative. Finally, we computed the design effect as a test of the 
sample size appropriateness, finding a widely satisfactory result of 367.853 (Satorra and Muthen 1995). This allowed us to conclude that the number of clusters and the associated average sample size were adequate for an accurate estimate of the parameters of interest.

Overall, these preliminary analyses suggested that it was legitimate and enlightening to consider the random variance of the hypothesized effects across the 23 European nations and that the quantity of clusters (i.e. nations) involved was adequate for their correct estimate.

Once the adequacy of a 1-1-1 multilevel mediation model was ascertained, it was necessary to carry out a restructuring of the variables and data matrix to estimate the random variation of the intercepts and slopes within it (Bauer et al. 2006). First, we centred the predictor and mediator within group, subtracting the group mean value from each individual's score of social exclusion and interpersonal trust. This allowed us to estimate the average within-group relationships between the predictor and the outcomes (i.e. $M=$ interpersonal trust; $Y=$ anti-immigration attitudes), as well as between mediator and criterion. We were thus able to interpret the intercept for a group $j$ as the expected response for individuals in group $j$ who have their average group response on the social exclusion or interpersonal trust measures (Enders and Tofighi 2007). Second, to obtain the covariance and asymptotic covariance matrices of the estimated parameters, we tested the different equations within a single model. Following the procedure of Bauer and colleagues (2006), rather than estimating through three separate equations (Kenny et al. 2003), the indirect effect was computed simultaneously in a unique equation, which allowed the estimation of the random covariance and asymptotic random covariance of the $a j$ and $b j$ paths. To do this, we stacked $M$ and $Y$ into a single variable labelled $Z$. We then created two dummy variables (conventionally labelled $S M$ and $S Y$ ) to be used as indicators for the variable $Z$, depending on the value it assumes (i.e. mediator or outcome). Rearranging data in this way allowed us to obtain the following general equation:

$$
Z i j=d M j S M i j+a j(S M i j X i j)+d Y j S Y i j+b j(S Y i j M i j)+c^{\prime} j(S Y i j X i j)+e Z i j
$$

Specifying the model in this fashion, it was therefore possible to extract the covariance matrix of all random effects, as well as the asymptotic sampling variance and covariance of these estimates. The latter was crucial for constructing the confidence intervals for the average indirect effects (Bauer et al. 2006). The sampling distribution of the indirect effect is not normally distributed and requires the use of an asymmetric confidence interval. For this reason, we obtained the confidence interval by the Monte Carlo Method (Replications =20,000; $C I=95 \%$ ), using the interactive tool provided by Preacher and Selig (2010).

Analyses were performed with the lme4 package (Bates et al. 2007) using RStudio (2015), a graphical interface for R software. The entire model was tested using a restricted maximum likelihood method (REML).

\section{Results}

First, we computed the correlations between the variables included in the model. Antiimmigration attitudes showed a positive correlation with social exclusion $(r=0.36$; $95 \% C I=0.35,0.37)$ and a negative correlation with interpersonal trust $(r=-0.31$; $95 \% C I=-0.32,-0.30)$. Social exclusion and interpersonal trust were also negatively correlated $(r=-0.34 ; 95 \% C I=-0.35,-0.33)$, as anticipated (see Table 2$)$. Given the growing recommendations in the literature about the importance of communicating the practical 


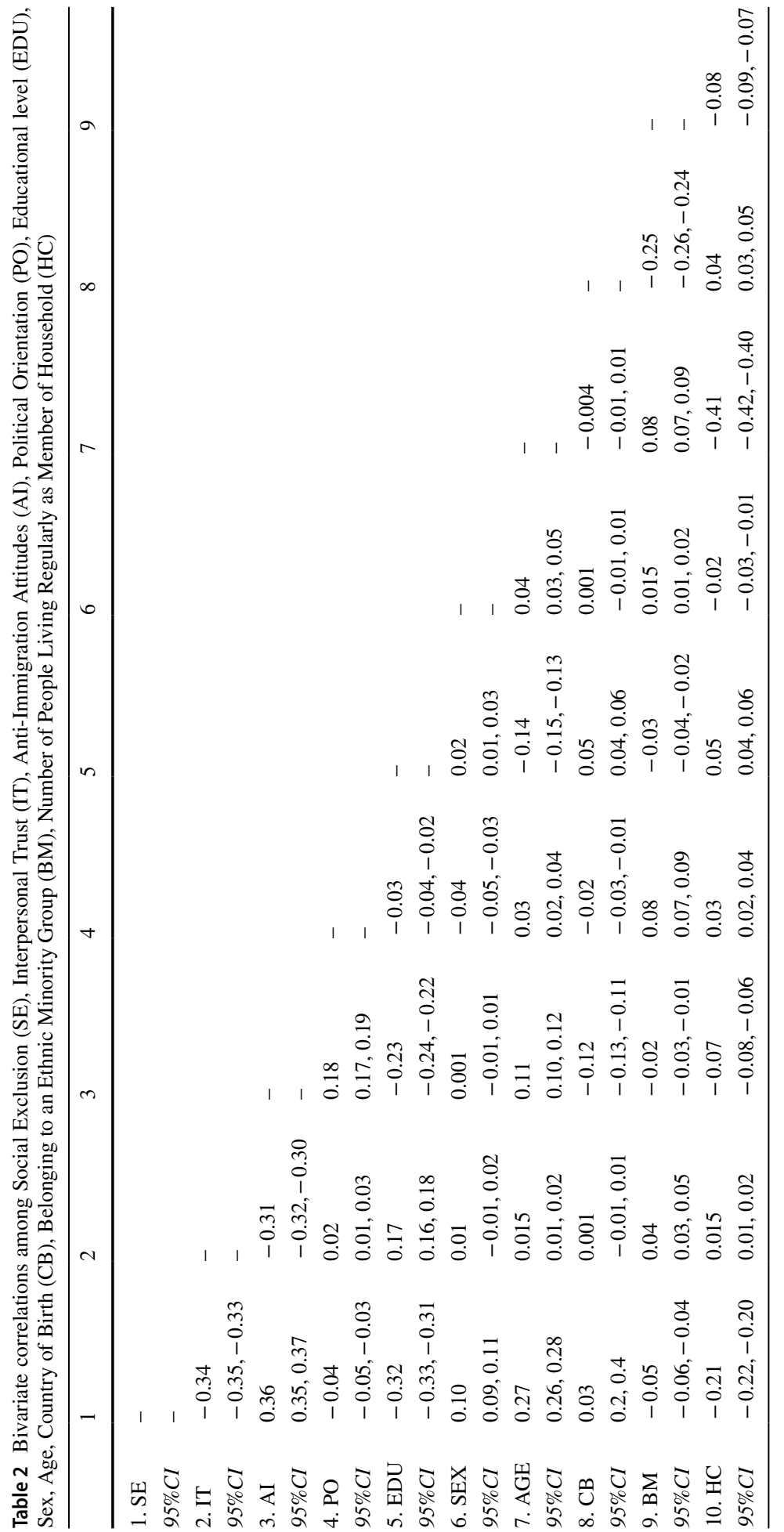


significance of results in psychological research (e.g. Lakens 2013), we decided to translate the resulting correlation coefficients in terms of effect size. We thus computed a Cohen's $d$ for each path of the relation tested. We obtained a Cohen's $d$ equal to 0.77 for the association between social exclusion and anti-immigration attitudes and of -0.72 for the relation between exclusion and interpersonal trust. Moreover, regarding the association of antiimmigration attitudes and interpersonal trust, the Cohen's $d$ was equal to -0.65 . Following the benchmarks provided by Cohen (1988), the strength of the associations among the variables of interest could be defined in terms of 'medium' effects. However, interpreting the effect sizes remains difficult even if translated into Cohen's $d$. As suggested by a recent review on effect size in the field of psychology (Funder and Ozer 2019), and as underlined also by Cohen himself (1988), the comparison parameters of the effects of a certain relationship must be addressed by the specific reference literature and in the related field of investigation. Therefore, to facilitate interpretation and foster a clear understanding of the strength of the associations among our variables, we decided to report the effect sizes in terms of a further index-the Number Needed to Treat (NNT; Altman and Andersen 1999; Cook and Sackett 1995). The $N N T$ is a measure of effect size, used in epidemiology to evaluate the effectiveness of an intervention that expresses the average number of patients to be treated to prevent a further negative outcome. The ideal value is 1 , meaning that there is a ratio of one patient who improves with treatment versus one who does not improve in the control group. Thus, following the procedure of Kraemer and Kupfer (2006), which allows the transformation of Cohen's $d$ into a version of NNT that is invariant to the event rate of the control group (see Furukawa and Leucht 2011), we obtained an NNT of 2.41 for the association between social exclusion and anti-immigration attitudes. This means that for about one person out of every two, the increase in social exclusion is accompanied by an increase in negative attitudes towards immigrants. Regarding the relationship between exclusion and interpersonal trust, we found an NNT equal to 2.56, which means that about one person out of every three tends to be less confident in others when the level of social exclusion is augmented. Finally, we found that about one individual for every three $(N N T=2.82)$ adopts more negative attitudes towards immigrant when he or she feels less generalized trust in others. If extended to the totality of the present sample, or even to the totality of the European population, these numbers become impressive, especially referring to the social psychological literature. Such results give a clear idea of the importance of the factors considered within the present study and provide relevant initial support for our expectations.

Going deeper into our focal analysis (i.e. 1-1-1 multilevel mediation) we obtained evidence in favour of our hypotheses. Recalling that all variables were rescaled in the 0 to 1 range, Table 3 shows that interpersonal trust was negatively affected by the purported antecedent variable of social exclusion $(B=-0.37 ; S E=0.014 ; t=-26.86 ; p<0.001$; $95 \% C I=-0.3984,-0.3442)$. This means that the level of exclusion negatively influenced the attribution of trust towards other people on average within all of the different nations (see Fig. 1), keeping the entered covariates constant. Anti-immigration attitudes, our criterion variable in the model, was significantly affected by both social exclusion $(B=0.26 ; S E=0.023 ; t=11.33 ; p<0.001 ; 95 \% C I=0.2110,0.2993)$ and interpersonal trust $(B=-0.23 ; S E=0.014 ; t=-17.06 ; p<0.001 ; 95 \% C I=-0.2611,-0.2073)$ on average within each cluster (see Figs. 2, 3, respectively). This highlights that anti-immigration attitudes increased as social exclusion increased and as interpersonal trust decreased. Note that these coefficients represent unique associations once the covariates were controlled for. Important for the purposes of our study, the within average indirect effect of social exclusion on anti-immigration attitudes through interpersonal trust was significant $(B=0.09$; 
Table 3 Fixed Effects of Social Exclusion on Interpersonal Trust (path a), Interpersonal Trust on AntiImmigration Attitudes (path b), the direct effect Social Exclusion on Anti-Immigration Attitudes (path c'), and the mediated effect by Interpersonal Trust of social exclusion on Anti-Immigration Attitudes. Political Orientation (PO), Educational level (EDU), Sex, Age, Country of Birth (CB), Belonging to an Ethnic Minority Group (BM), Number of People Living Regularly as Member of Household (HC) are the covariates inserted into the analysis model

\begin{tabular}{|c|c|c|c|c|c|c|}
\hline \multirow[b]{2}{*}{ Parameters } & \multirow[b]{2}{*}{$B$} & \multirow[b]{2}{*}{$S E$} & \multirow[b]{2}{*}{$t$} & \multirow[b]{2}{*}{$p$} & \multicolumn{2}{|l|}{$95 \% C I s$} \\
\hline & & & & & Lower & Upper \\
\hline Path a & -0.371 & 0.014 & -26.86 & $<0.001$ & -0.3984 & -.3442 \\
\hline $\mathrm{PO}$ & -0.006 & 0.005 & -1.44 & 0.15 & -0.0138 & 0.0021 \\
\hline EDU & 0.034 & 0.003 & 10.67 & $<0.001$ & 0.0279 & 0.0405 \\
\hline SEX & 0.014 & 0.002 & 7.81 & $<0.001$ & 0.0104 & 0.0174 \\
\hline AGE & 0.085 & 0.005 & 18.25 & $<0.001$ & 0.0757 & 0.0940 \\
\hline $\mathrm{CB}$ & -0.006 & 0.003 & -2.08 & 0.037 & -0.0126 & -0.0004 \\
\hline $\mathrm{BM}$ & 0.019 & 0.004 & 4.93 & $<0.001$ & 0.0116 & 0.0269 \\
\hline $\mathrm{HC}$ & 0.012 & 0.014 & 0.85 & 0.39 & -0.0155 & 0.0392 \\
\hline Path b & -0.234 & 0.014 & -17.06 & $<0.001$ & -0.2611 & -0.2073 \\
\hline Path c' & 0.255 & 0.023 & 11.33 & $<0.001$ & 0.2110 & 0.2993 \\
\hline $\mathrm{PO}$ & 0.149 & 0.004 & 36.72 & $<0.001$ & 0.1419 & 0.1579 \\
\hline EDU & -0.101 & 0.003 & -31.14 & $<0.001$ & -0.1067 & -0.0941 \\
\hline SEX & -0.009 & 0.002 & -4.90 & $<0.001$ & -0.0122 & 0.0052 \\
\hline AGE & 0.063 & 0.005 & 13.45 & $<0.001$ & 0.0504 & 0.0725 \\
\hline $\mathrm{CB}$ & -0.070 & 0.003 & -22.25 & $<0.001$ & -0.0759 & -0.0636 \\
\hline $\mathrm{BM}$ & -0.031 & 0.004 & -8.02 & $<0.001$ & -0.0391 & -0.0238 \\
\hline \multirow[t]{3}{*}{$\mathrm{HC}$} & 0.055 & 0.014 & 3.93 & $<0.001$ & 0.0276 & 0.0824 \\
\hline & & & & & \multicolumn{2}{|c|}{ Monte Carlo $95 \%$ CI } \\
\hline & $B$ & $S E$ & $Z$ & $p$ & Lower & Upper \\
\hline Indirect effect & 0.089 & 0.007 & 13.04 & $<0.001$ & 0.0752 & 0.1027 \\
\hline
\end{tabular}

$S E=0.007 ; Z=13.04 ; p<0.001 ; M C 95 \% C I=0.0752,0.1027)$. Such results indicate that, on average inside each country, as social exclusion increased a decrease could be observed in trust, which in turn related with an increase in negative attitudes towards immigrants. The social exclusion effect, mediated by interpersonal trust, positively affected the onset of anti-immigration attitudes also when the random variability of the $a j$ and $b j$ paths, due to countries in which the participants lived, was considered in the analysis model. A graphical representation of the mediation paths can be seen in Fig. 4.

To ease the interpretation of the emerged fixed effects and to quantify their magnitude, we computed a marginal $R^{2}\left(R_{L M M(m)}^{2}\right)$ of the interested parameters, as indicated by Nakagawa et al. (2017). Afterwards, we converted the marginal $R^{2}$ into semi-partial correlations, which in turn were translated into Cohen's $d$. We then discussed their relevance in terms of NNT (see Table 4). In this way, we found a Cohen's $d$ of 0.30 for the association between social exclusion and interpersonal trust, which corresponded to an NNT of 5.95. For path $b$ (i.e. the relation between trust and anti-immigration attitudes), the analysis showed a Cohen's $d$ equal to 0.28 and an NNT of 6.26, highlighting the high magnitude of this relationship. Regarding the direct linkage of social exclusion and anti-immigration 


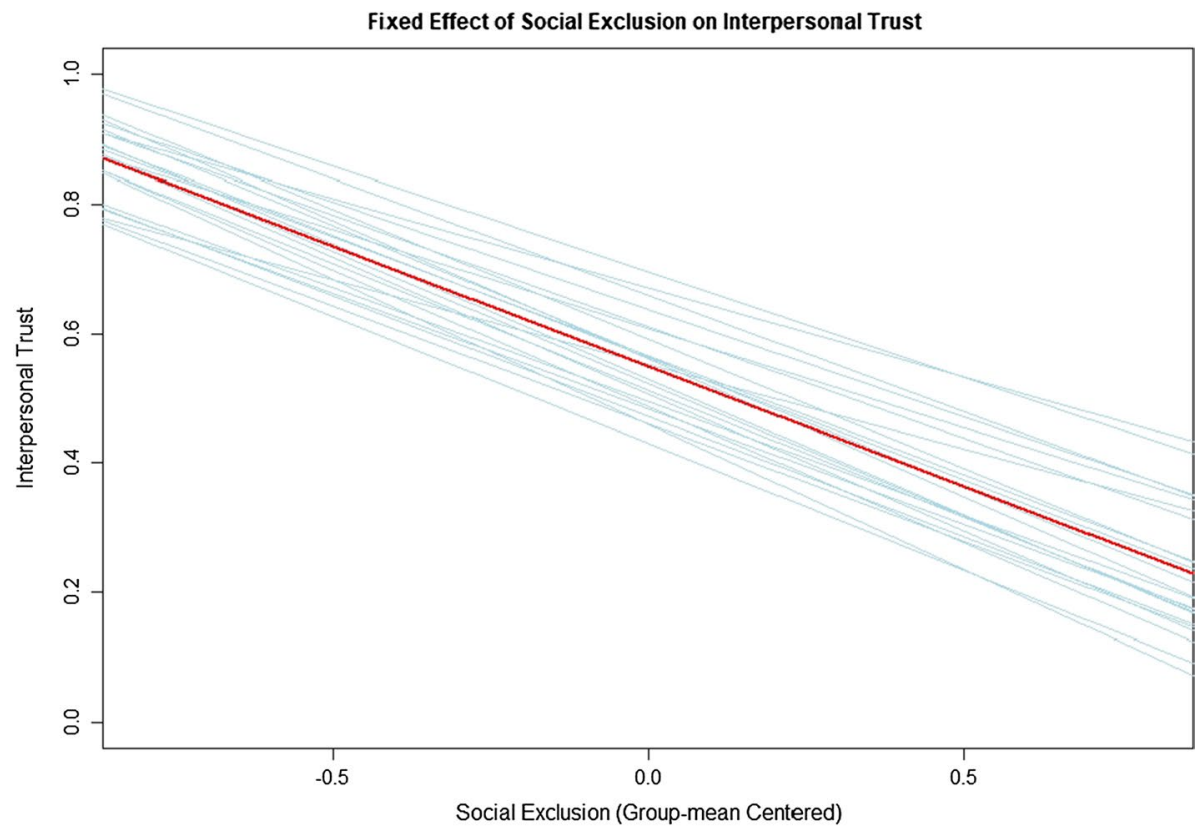

Fig. 1 Fixed Effect of Social Exclusion on Interpersonal Trust; red line represents the fixed effect and blue lines random effects

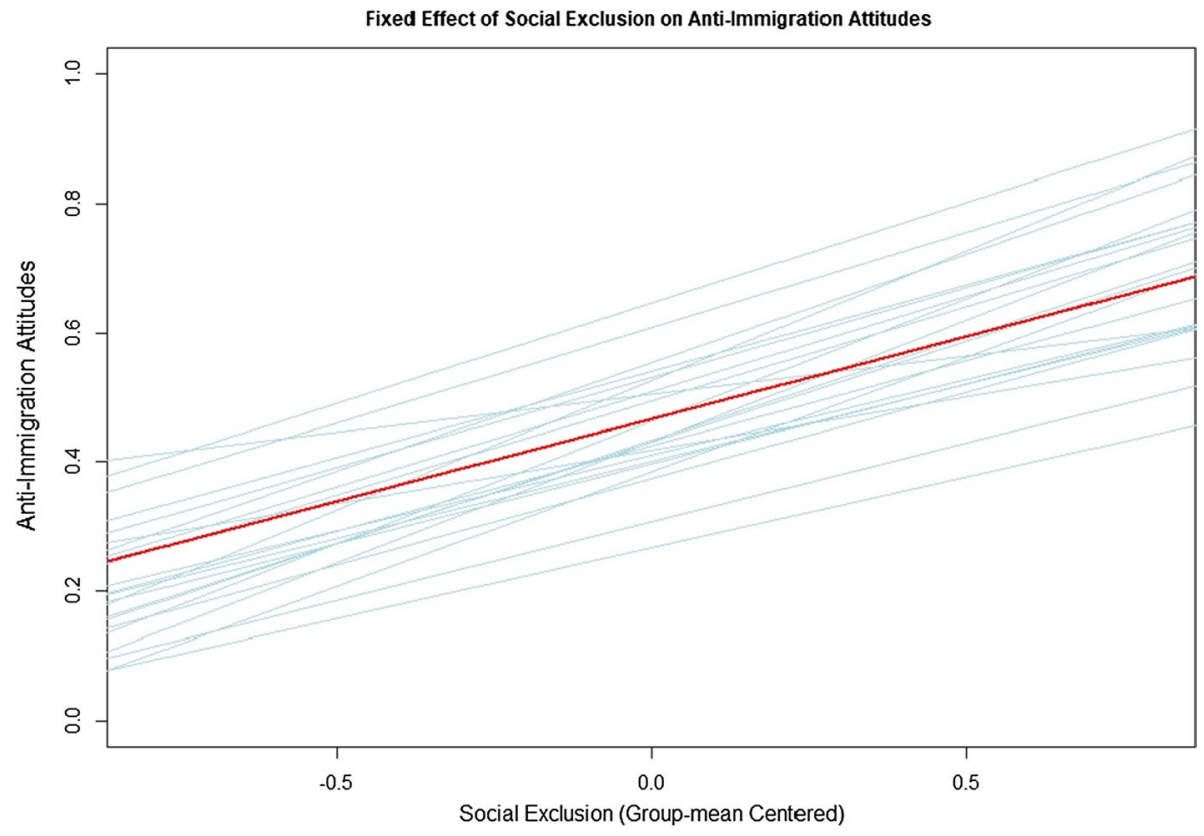

Fig. 2 Fixed Effect of Social Exclusion on Anti-Immigration Attitudes; red line represents the fixed effect and blue lines random effects 


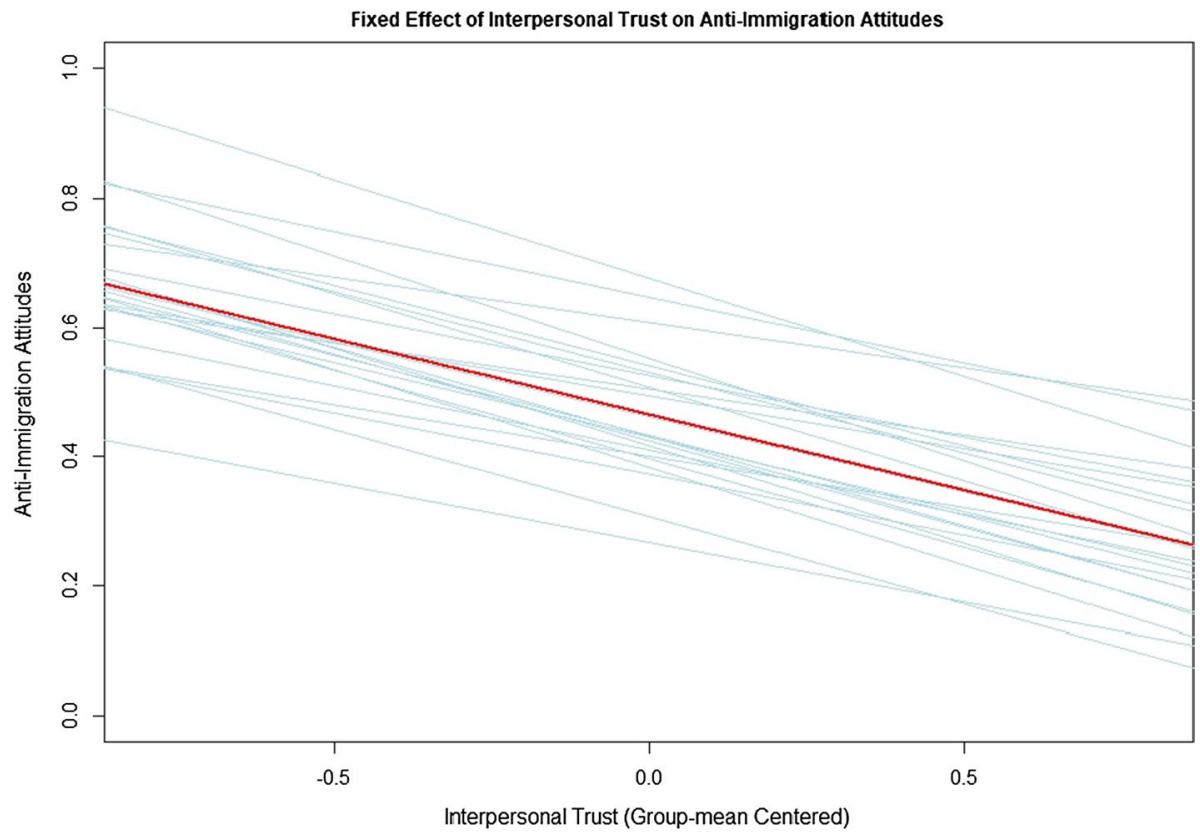

Fig. 3 Fixed Effect of Interpersonal Trust on Anti-Immigration Attitudes; red line represents the fixed effect and blue lines random effects

Level 2

23 European Countries

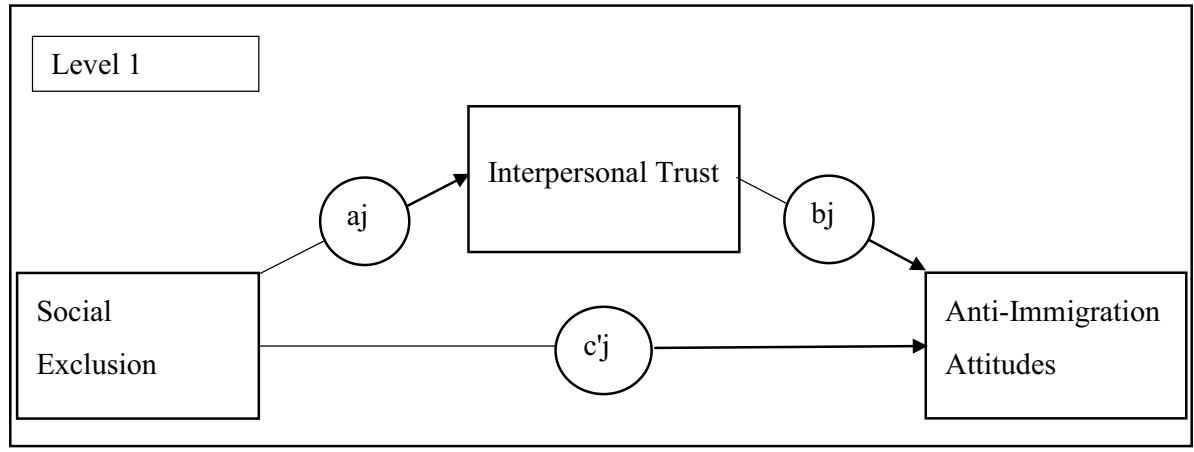

Fig. 4 Graphical representation of the 1-1-1 Multilevel Mediational Model

attitudes, the Cohen's $d$ corresponded to 0.20 with an NNT equal to 8.84. Making an approximating estimate within the sample under investigation, this meant that a decrease of interpersonal trust due to the experience of social exclusion could concern about 7,460 individuals. The emergence of anti-immigration attitudes because of a decrease of trust could involve about 7,090 persons. Considering the direct association between social 
Table 4 Practical magnitude of fixed effects. Table reports marginal square $\mathrm{R}\left(\mathrm{R}^{2}{ }_{(\mathrm{m})}\right)$, semi-partial correlations $\left(r_{\mathrm{sp}}\right.$, Cohen's d, and Number Needed to Treat (NNT) for the associations between Social Exclusion and Interpersonal Trust (Path a), Interpersonal Trust and Anti-Immigration Attitudes (Path b), Social Exclusion and Anti-Immigration Attitudes (Path c')

\begin{tabular}{llllr}
\hline Parameters & $\mathrm{R}_{(\mathrm{m})}^{2}$ & $\mathrm{r}_{\mathrm{sp}}$ & $\mathrm{d}$ & $\mathrm{NNT}$ \\
\hline Path a & 0.022 & 0.148 & 0.30 & 5.95 \\
Path b & 0.020 & 0.141 & 0.28 & 6.26 \\
Path c' & 0.010 & 0.100 & 0.20 & 8.84 \\
\hline
\end{tabular}

exclusion and anti-immigration attitudes, the number of involved individuals became equal to 5,021. If-with due caution-we extended these estimates to the entire European population, the relevance of the investigated factors distinctly appears.

To provide a better and more complete understanding that clarifies the diverse nuances that the emerged relationships can assume in the different European countries, it was key to explore the random effects. With some variations in baselines and relatively minor differences in slopes within each member state, the investigated relationships were consistent with what we hypothesized. As can be seen in Table 5, interpersonal trust $(B=0.005$; $S E=0.002 ; Z=3.31 ; p<0.001 ; 95 \% C I=0.0029,0.0097)$ and anti-immigration attitudes $(B=0.01 ; S E=0.003 ; Z=3.31 ; p<0.001 ; 95 \% C I=0.0056,0.0183)$ differed in their baselines among countries. This indicates that the starting level of anti-immigration attitudes, as well as that of trust between people, varied considerably across the different countries of the European Union (see Fig. 5). On the other hand, the analysis revealed small variation regarding random slopes. Although we found significant random variances for the relationships between predictor, mediator, and outcome, the differences across countries appeared to be quite small. Indeed, the random effect of social exclusion on interpersonal trust $(B=0.003 ; S E=0.001 ; Z=2.83 ; p=0.005 ; 95 \% C I=0.0015,0.0061)$ highlighted that, although with a minimum variation across countries, excluded individuals tended to be less confident about other people. As shown in Fig. 6, social exclusion exerted a negative impact on interpersonal trust in each of the 23 countries, with relatively more pronounced slopes in Italy, Slovenia, Germany, Portugal, Czech Republic, Hungary, Austria, and France. Figure 7 shows that within each member state, poor interpersonal trust led people to assume hostile attitudes towards immigrants and immigration in general. Even if the slopes randomly varied across countries $(B=0.004 ; S E=0.001 ; Z=3.01 ; p=0.003 ; 95 \% C I=0.0021$, 0.0076), reduced interpersonal trust positively influenced the emergence of anti-immigration attitudes in the countries considered. Such slopes were relatively strong in many of the countries examined (i.e. Italy, Germany, Austria, France, Spain, the Netherlands, Slovenia,

Table 5 Random Effects of the model. Table reports random intercepts of Interpersonal Trust and Anti-Immigration Attitudes, random slopes of Social Exclusion on Interpersonal Trust (path a), Interpersonal Trust on Anti-Immigration Attitudes (path b), and of Social Exclusion on Anti-Immigration Attitudes (path c')

\begin{tabular}{|c|c|c|c|c|c|c|}
\hline \multirow[b]{2}{*}{ Parameters } & \multirow[b]{2}{*}{$B$} & \multirow[b]{2}{*}{$S E$} & \multirow[b]{2}{*}{$Z$} & \multirow[b]{2}{*}{$p$} & \multicolumn{2}{|c|}{$95 \%$ CIs } \\
\hline & & & & & Lower & Upper \\
\hline Intercept Trust & 0.005 & 0.002 & 3.31 & $<0.001$ & 0.0029 & 0.0097 \\
\hline Intercept Anti-Imm & 0.010 & 0.003 & 3.31 & $<0.001$ & 0.0056 & 0.0183 \\
\hline Slope path a & 0.003 & 0.001 & 2.83 & 0.005 & 0.0015 & 0.0061 \\
\hline Slope path b & 0.004 & 0.001 & 3.01 & 0.003 & 0.0021 & 0.0076 \\
\hline Slope path c' & 0.010 & 0.003 & 3.12 & 0.002 & 0.0056 & 0.0198 \\
\hline
\end{tabular}




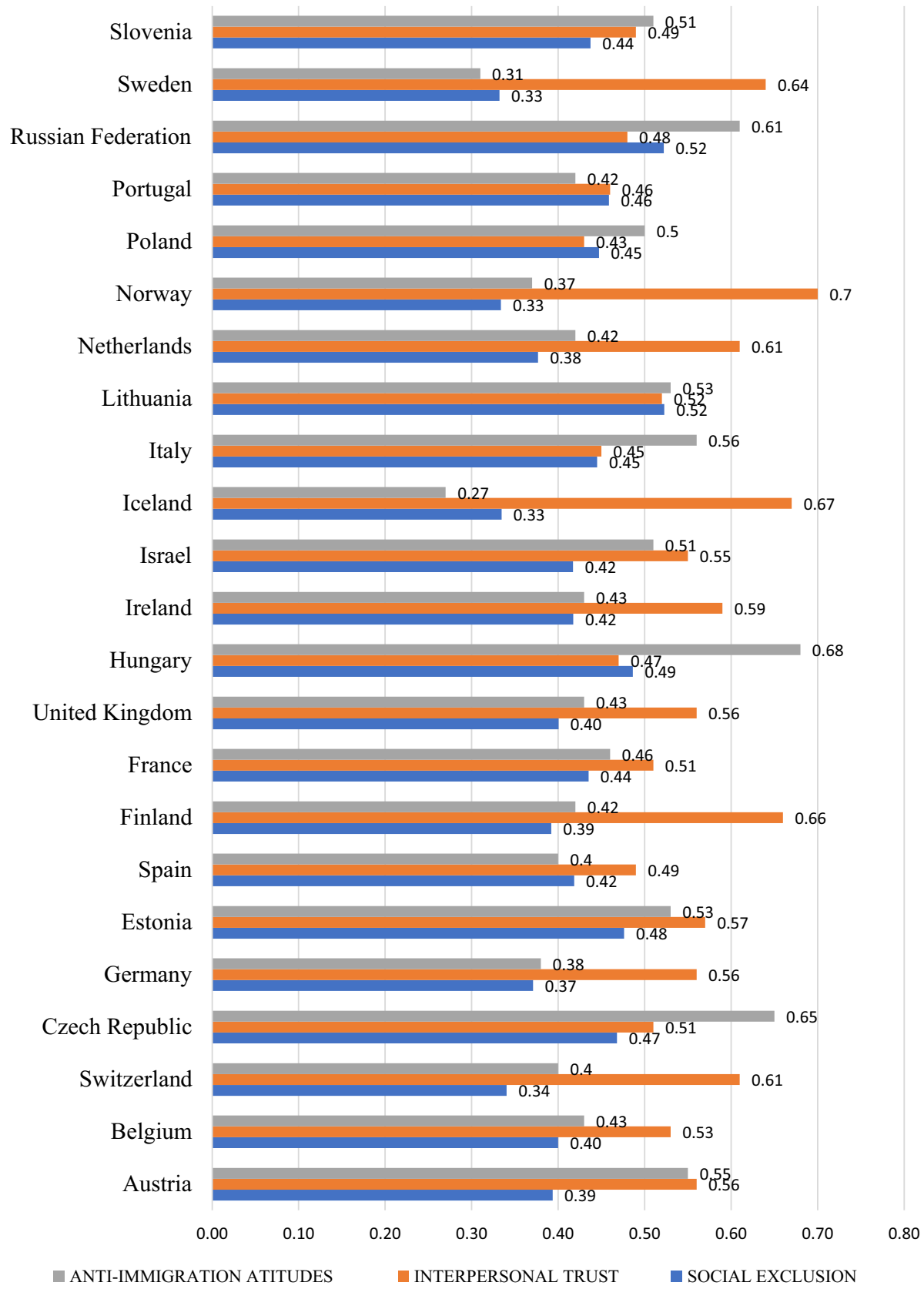

Fig. 5 Within Nations average scores for Social Exclusion, Interpersonal Trust and Anti-Immigration Attitudes. Score ranged between 0 and 1

Ireland, the United Kingdom, Belgium, Finland, Portugal, and Sweden). A similar result was also found considering the direct association of social exclusion and anti-immigration attitudes. The random variability of the slopes was barely noticeable $(B=0.01 ; S E=0.003$; 


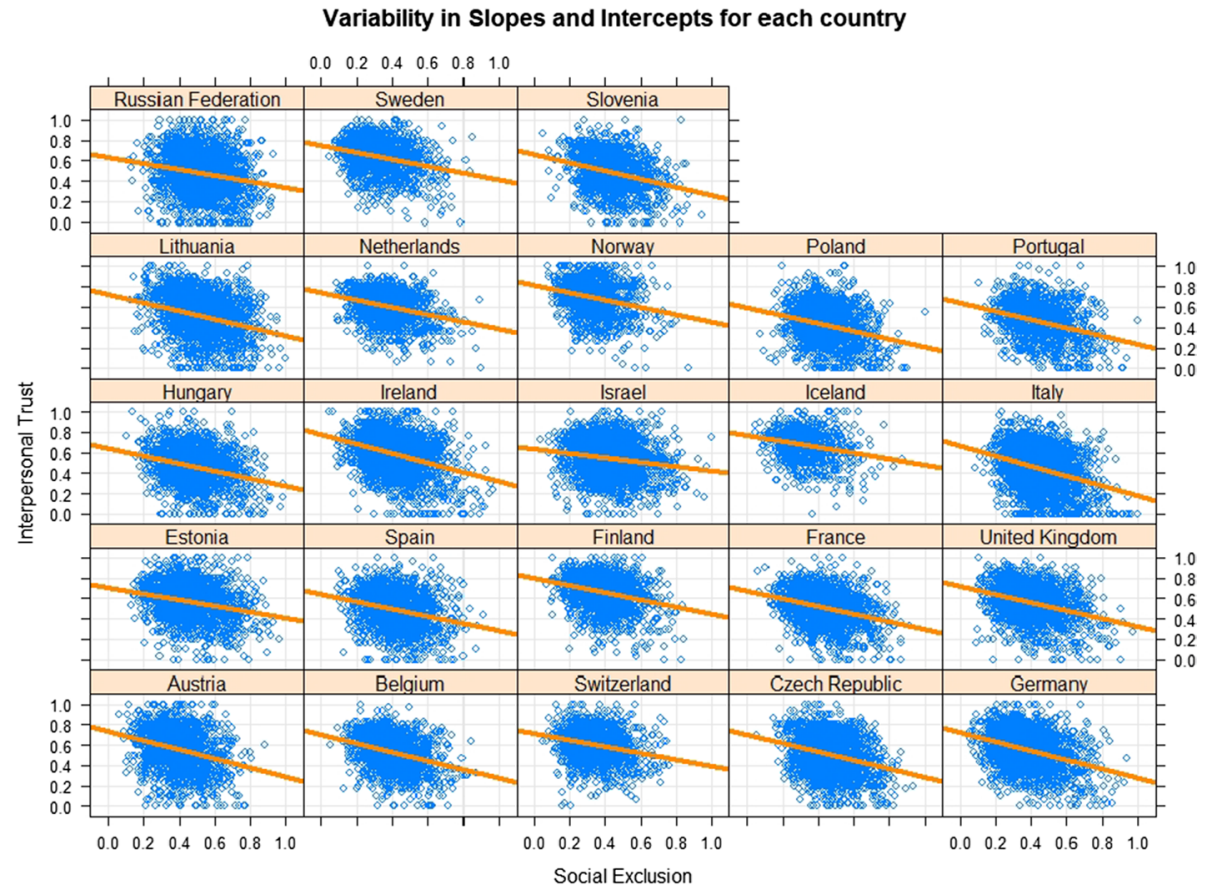

Fig. 6 Random variability of the association between Social Exclusion and Interpersonal Trust across the 23 European Nations

$Z=3.12 ; p=0.002 ; 95 \% C I=0.0056,0.0198)$, confirming that, in general across countries, the higher the perceptions of social exclusion, the higher and more negative the attitudes towards immigrants (see Fig. 8). Some exceptions, in which the direct associations of trust and exclusion with anti-immigration attitudes seemed to be slightly weak, were represented by the Russian Federation, the Czech Republic, and Hungary.

\section{General Discussion}

The present study investigated whether the experience of social exclusion could be associated with a reduction in generalized trust towards other people that, in turn, would have led to hostile attitudes towards immigrants and immigration. Despite the multiplicity of studies on the possible antecedents of the emergence of anti-immigration attitudes, none have analysed the possible role that social exclusion and interpersonal trust together could play. Specifically, none have examined how both could jointly shape the rise of negative sentiment against people fleeing from wars and persecution, as well as against those who decide to live in a country other than their country of origin.

The direct positive effect of social exclusion on the emergence of anti-immigration attitudes we have found provides some support for the idea that people who experience a state of social exclusion tend to adopt a more hostile attitude towards immigrants. This effect appeared to be consistent across the European Union. To date, the association of social exclusion and anti-immigration attitudes has more often been investigated focusing on the 
Variability in Slopes and Intercepts for each country

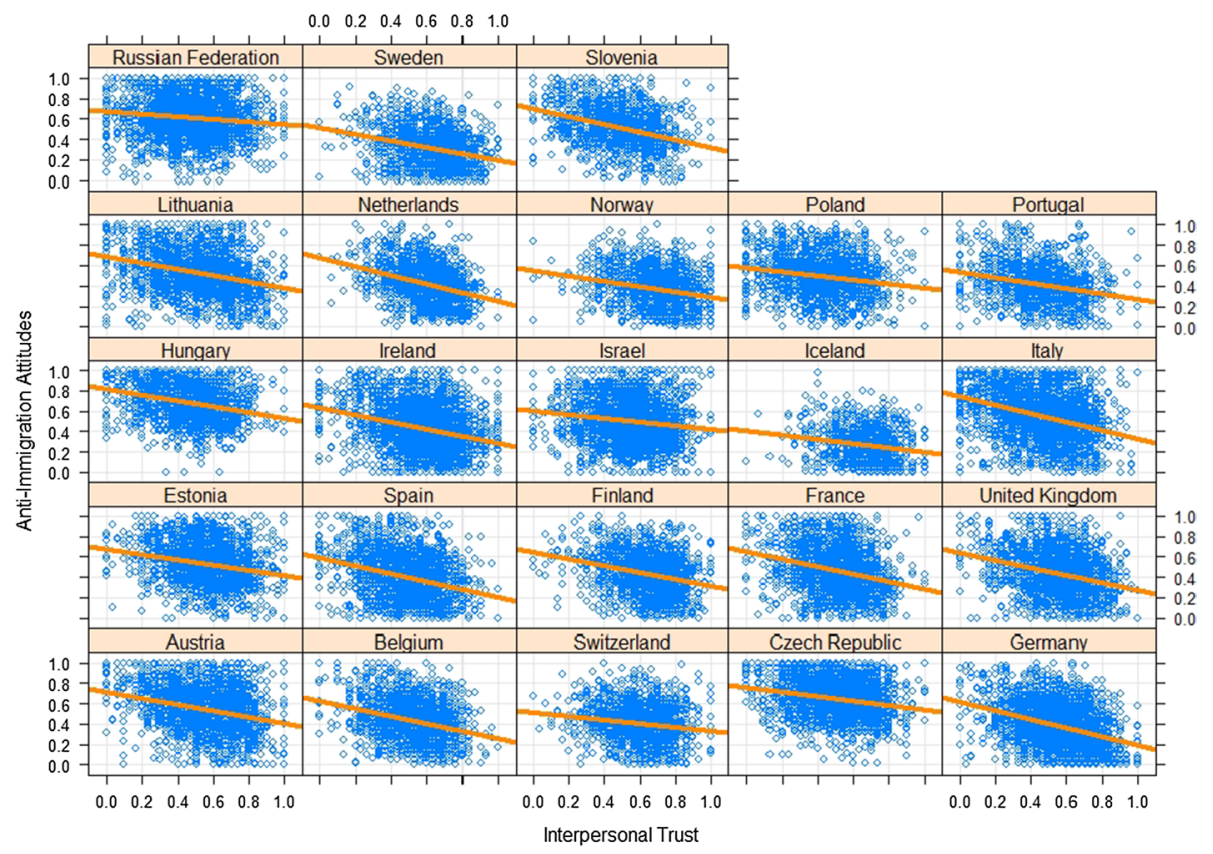

Fig. 7 Random variability of the association between Interpersonal Trust and Anti-Immigration Attitudes across the 23 European Nations

exclusion experienced by immigrants as a case study (e.g. Gradstein and Schiff 2006). As previously specified, such studies have focused on social exclusion in terms of the different integration levels of an immigrant in the new country. The study presented here thus contributes to the literature by showing that social exclusion experienced by natives can represent an antecedent of the appearance of negative attitudes towards immigrants in a hosting country. Moreover, this study complements existing evidence regarding the effect of economic (Facchini and Mayda 2009; Hanson et al. 2007; Mayda 2006; Scheve and Slaughter 2001), cultural (e.g. Rustenbach 2010), and social identity factors (e.g. Roets and Van Hiel 2011) on anti-immigrant attitudes. By focusing on social exclusion as a multidimensional construct involving different life domains such as the economic, cultural, and social (Levitas et al. 2007), we provide insights for an integrative perspective on how and reasons why natives develop negative attitudes towards immigrants.

Moreover, as emerged from our study, feelings of generalized interpersonal trust were key in explaining the relationship between social exclusion and anti-immigrant attitudes. Indeed, we found that increases in social exclusion were paired with decreases in generalized trust. As described above, the deprivations in different spheres that compose a person's life place him or her in a condition of social exclusion. When individuals are unable to participate over time in certain of their society's activities, for reasons beyond their control, they inevitably identify the cause of their condition of exclusion in the social system to which they belongs and in the people by whom it is composed. In this way, the implicit and intrinsic act of belonging to a community is betrayed and the trust placed in the people who are part of it declines. When this condition becomes 
Variability in Slopes and Intercepts for each country

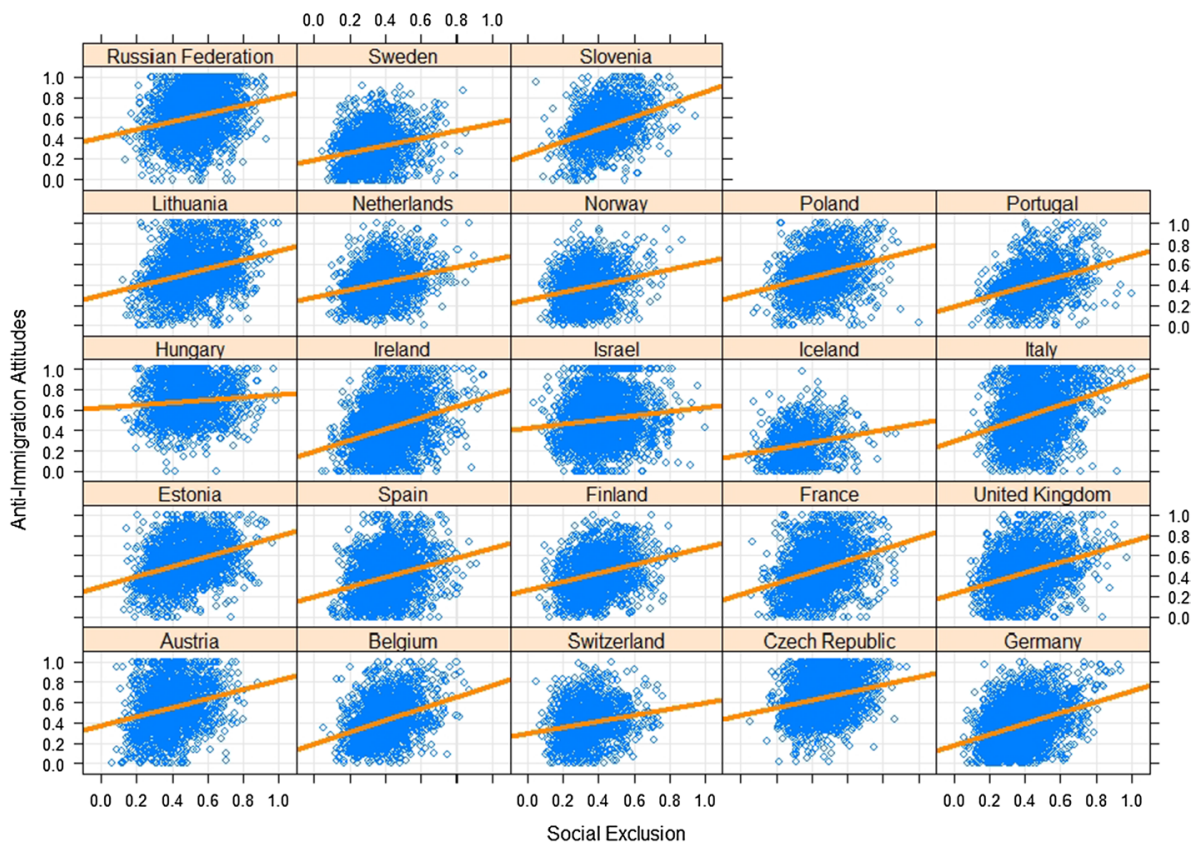

Fig. 8 Random variability of the association between Social Exclusion and Anti-Immigration Attitudes across the 23 European Nations

widespread and permanent, a generalized sense of distrust in other people is engendered (Burchardt 2000). Thus, consistently with what emerged in the studies of Twenge and colleagues (2007), our results supported the idea that socially excluded people are motivated by the desire to protect themselves from the possibility of further instances of social exclusion, adopting a cautious and suspicious attitude towards unknown people, of which immigrants represent a vivid instance.

Because of the lack of shared factors (e.g. norms, values, beliefs) upon which to build interpersonal trust, individuals from different ethnic groups are typically perceived negatively by natives. Accordingly, we found that interpersonal trust correlated negatively with anti-immigration attitudes. In other words, our results showed that as confidence in generalized others increased, there was a reduction in hostile sentiments towards immigrants. This result is in line with what Rustenbach (2010) highlighted in her study, finding in interpersonal trust the strongest predictor of anti-immigrant attitudes.

Importantly, the present study also speaks about a further relevant aspect that previous research had not addressed. It showed that a generalized sense of distrust towards people mediated the association between social exclusion and the rise of negative sentiments towards immigrants. In addition, we found that the average indirect effect of social exclusion through interpersonal trust had a positive impact on anti-immigration attitudes across representative samples of 23 European countries.

In summary, our findings may disambiguate the apparently conflicting results deriving from the social psychology research on exclusion, which showed that excluded people tended both to be closed and antisocial (Baumeister et al. 2005; Gest et al. 2001; 
Twenge et al. 2001) and willing to collaborate and cooperate (Maner et al. 2007; Williams and Sommer 1997). We believe that both results are reliable, but that they missed an important factor in explaining the negative or positive consequences of the experience of social exclusion. This factor is represented by the reduction of trust towards others. Consistent with Twenge and colleagues (2007), our findings support the notion that the attitudes and behaviours of the excluded person are governed by the search for a delicate balance between a dual and interconnected objective: on the one hand, the establishment and maintenance of new relationships and, on the other hand, protecting oneself from the possibility of being rejected and excluded again. The excluded persons might thus actually be interested in developing new relationships, but the negative past experience of exclusion leads them to be reluctant to expose themselves to the risk of being hurt again. Such lack of trust towards others, due to instances of exclusion, leads individuals to be diffident and to adopt negative attitudes towards unknown people. In other words, the doubt and suspicion that individuals experience about generalized other (low interpersonal trust), related to the experienced condition of social exclusion, favours a negative evaluation of unknown people from different cultures, who may have values and standards perceived as distant from those of the native population.

These results are also reflected in the analysis of the random effects. Although with some variation in baselines and slopes within each member state, the investigated relationships are consistent with what we hypothesized. As the analysis of the random slopes clearly showed, the negative relationships between social exclusion and interpersonal trust and between trust and anti-immigration attitudes, as well as the positive relationship between social exclusion and anti-immigration attitudes, remained similar regardless of the nation examined. We believe this increases the accuracy of our findings and supports their generalizability to the population of the European community.

\section{Limits and Future Directions}

Some limitations need to be acknowledged. First, the correlational and cross-sectional nature of the data prevented us from making causal inferences. Although the main aim of this work was to establish a model of associations between the constructs of social exclusion, interpersonal trust, and anti-immigration attitudes, future studies are encouraged to examine the causal nature of these associations. For instance, a double causality between the experience of social exclusion and feelings of interpersonal trust could be hypothesized.

Another limitation may be represented by the operationalization of the social exclusion construct. As highlighted by both the B-SEM (Levitas et al. 2007) and SEM (Scutella et al. 2009), social exclusion represents a multidimensional process that involves several areas of an individual's life. We relied on several indicators which, according to the literature, appeared to be adequate in representing the three main dimensions of social exclusion-that is, resources, participation, and quality of life. However, it would be desirable to replicate our proposed model by including some minor, but relevant, factors of social exclusion such as people's mobility linked to transport access.

Finally, a limitation emerged in the analysis of the random slopes. Indeed, we found that the Russian Federation, the Czech Republic, and Hungary represented cases where the direct effect of trust and exclusion on anti-immigration attitudes seemed to be weaker than in other countries. However, those countries share a common elevated baseline of antiimmigration attitudes compared with other states. This may have mitigated the effects of 
the predictors considered in the present study, because of range restriction. Future research could investigate the psychological dynamics related to the emergence of hostile feelings towards immigrants, taking as a specific case study the peculiar situations characterizing these nations. Otherwise, future research could try to investigate the relationships between experienced social exclusion, feelings of generalized interpersonal trust, and anti-immigration attitudes by focusing on different levels of analysis. As an example, implementing a 2-2-1 or 2-1-1 multilevel mediation model could be a possibility.

\section{Conclusion}

Overall, the present work sheds light on the importance of some aspects that might defuse hostility towards immigrants. Although many studies have investigated the possible causes of the emergence of hostile attitudes towards immigrants, to the best of our knowledge, none has tried to examine the possible role that social exclusion and interpersonal trust may jointly have. Our study has tried to address this gap in the literature, offering a new perspective on individual-level processes that can favour hostile and prejudicial attitudes between ethnic groups. This explanation provides an original potential point of view about the momentous social change determined by immigration in Europe and around the world.

The use of a multilevel mediation model, which took into account the random variability of the indirect effect across the examined European nations, provided greater robustness and generalizability for the results obtained. The analyses of the effect sizes carried out on the correlations between the variables of interest, as well as on the multilevel mediation model's results, provided a clear view of the importance of the factors considered in the present study and how practical intervention on them may lead to a broad spectrum of changes. Community policies could implement interventions aimed at the achievement of economic and social equality that should reduce the state of exclusion experienced by important sections of the European population. This should, in turn, promote the development of a climate of mutual trust and acceptance among individuals.

Funding Open Access funding provided by Università degli Studi di Roma La Sapienza. This study was not funded by any grant.

\section{Compliance with Ethical Standards}

Conflict of interest The authors declare that they have no conflict of interest.

Ethical Approval All procedures performed in studies involving human participants were in accordance with the ethical standards of the institutional and national research committee and with the 1964 Helsinki declaration and its later amendments or comparable ethical standards.

Human and Animal Rights This article does not contain any studies with animals performed by any of the authors.

Open Access This article is licensed under a Creative Commons Attribution 4.0 International License, which permits use, sharing, adaptation, distribution and reproduction in any medium or format, as long as you give appropriate credit to the original author(s) and the source, provide a link to the Creative Commons licence, and indicate if changes were made. The images or other third party material in this article are included in the article's Creative Commons licence, unless indicated otherwise in a credit line to the 
material. If material is not included in the article's Creative Commons licence and your intended use is not permitted by statutory regulation or exceeds the permitted use, you will need to obtain permission directly from the copyright holder. To view a copy of this licence, visit http://creativecommons.org/licenses/by/4.0/.

\section{References}

Altman, D. G., \& Andersen, P. K. (1999). Calculating the number needed to treat for trials where the outcome is time to an event. BMJ, 319(7223), 1492-1495. https://doi.org/10.1136/bmj.319.7223.1492.

Arikan, G., \& Sekercioglu, E. (2019). Authoritarian predispositions and attitudes towards redistribution. Political Psychology. https://doi.org/10.1111/pops.12580.

Bates, D., Sarkar, D., Bates, M. D., \& Matrix, L. (2007). The lme4 package. R package version, $2(1), 74$.

Bauer, D. J., Preacher, K. J., \& Gil, K. M. (2006). Conceptualizing and testing random indirect effects and moderated mediation in multilevel models: New procedures and recommendations. Psychological methods, 11(2), 142. https://doi.org/10.1037/1082-989X.11.2.142.

Baumeister, R. F., DeWall, C. N., Ciarocco, N. J., \& Twenge, J. M. (2005). Social exclusion impairs self-regulation. Journal of personality and social psychology, 88(4), 589. https://doi. org/10.1037/0022-3514.88.4.589.

Baumeister, R. F., \& Leary, M. R. (1995). The need to belong: desire for interpersonal attachments as a fundamental human motivation. Psychological bulletin, 117(3), 497.

Brown, R. (2011). Prejudice: Its social psychology. United States: Wiley.

Burchardt, T. (2000). Concepts and Evidence (pp. 385-406). Breadline Europe: The measurement of poverty.

Cavaillé, C., \& Marshall, J. (2019). Education and anti-immigration attitudes: Evidence from compulsory schooling reforms across Western Europe. American Political Science Review, 113(1), 254263. https://doi.org/10.1017/S0003055418000588.

Chang, H. I., \& Kang, W. C. (2018). Trust, economic development and attitudes toward immigration. Canadian Journal of Political Science/Revue canadienne de science politique, 51(2), 357-378. https://doi.org/10.1017/S0008423917001378.

Cohen, J. (1988). Statistical power analysis for the behavioral sciences (2nd ed.). New York: Academic.

Cook, R. J., \& Sackett, D. L. (1995). The number needed to treat: a clinically useful measure of treatment effect. BMJ, 310(6977), 452-454. https://doi.org/10.1136/bmj.310.6977.452.

De Cristofaro, V., Pellegrini, V., Baldner, C., van Zomeren, M., Livi, S., \& Pierro, A. (2019). Need for closure effect on collective action intentions and behavior toward immigrants in Italy the mediation of binding foundations and political conservatism. Journal of Applied Social Psychology. https:// doi.org/10.1111/jasp.12620.

Enders, C. K., \& Tofighi, D. (2007). Centering predictor variables in cross-sectional multilevel models: A new look at an old issue. Psychological methods, 12(2), 121. https://doi.org/10.1037/1082989X.12.2.121.supp.

European Social Survey. (2017). ESS Round 8 (2016/2017) Technical Report. London: ESS ERIC.

ESS Round 8: European Social Survey Round 8 Data (2016). Data file edition 2.1. NSD - Norwegian Centre for Research Data, Norway-Data Archive and distributor of ESS data for ESS ERIC. https:// doi.org/10.21338/NSD-ESS8-2016.

Eurostat, E. U. (2018). Living conditions in Europe - social participation and integration. Available online: https://ec.europa.eu/eurostat/statistics-explained/index.php/Living_conditions_in_Europ e_-_social_participation_and_integration.

Eurostat, E. U. (2019). People at risk of poverty or social exclusion. Available online: https://ec.europ a.eu/eurostat/statistics-explained/index.php?title=Archive:People_at_risk_of_poverty_or_socia 1_exclusion.

Facchini, G., \& Mayda, A. M. (2009). Does the welfare state affect individual attitudes toward immigrants? Evidence across countries. The review of economics and statistics, 91(2), 295-314. https:// doi.org/10.1162/rest.91.2.295.

Fukuyama, F. (1995). Trust: The social virtues and the creation of prosperity (Vol. 99). New York: Free press.

Funder, D. C., \& Ozer, D. J. (2019). Evaluating effect size in psychological research: Sense and nonsense. Advances in Methods and Practices in Psychological Science, 2(2), 156-168. https://doi. org/10.1177/2515245919847202. 
Furukawa, T. A., \& Leucht, S. (2011). How to obtain NNT from Cohen's d: Comparison of two methods. PLoS ONE, 6(4), e19070. https://doi.org/10.1371/journal.pone.0019070.

Gest, S. D., Graham-Bermann, S. A., \& Hartup, W. W. (2001). Peer experience: Common and unique features of number of friendships, social network centrality, and sociometric status. Social development, 10(1), 23-40. https://doi.org/10.1111/1467-9507.00146.

Gradstein, M., \& Schiff, M. (2006). The political economy of social exclusion, with implications for immigration policy. Journal of Population Economics, 19(2), 327-344. https://doi.org/10.1007/ s00148-005-0016-0.

Hanson, G. H., Scheve, K., \& Slaughter, M. J. (2007). Public finance and individual preferences over globalization strategies. Economics \& Politics, 19(1), 1-33. https://doi.org/10.111 1/j.1468-0343.2007.00300.x.

Hardin, R. (2002). Trust and trustworthiness. New York: Russell Sage Foundation.

Hayes, A. F. (2006). A primer on multilevel modeling. Human communication research, 32(4), 385-410. https://doi.org/10.1111/j.1468-2958.2006.00281.x.

Herreros, F., \& Criado, H. (2009). Social trust, social capital and perceptions of immigration. Political studies, 57(2), 337-355. https://doi.org/10.1111/j.1467-9248.2008.00738.x.

Kenny, D. A., Korchmaros, J. D., \& Bolger, N. (2003). Lower level mediation in multilevel models. Psychological methods, 8(2), 115. https://doi.org/10.1037/1082-989X.8.2.11.

Kraemer, H. C., \& Kupfer, D. J. (2006). Size of treatment effects and their importance to clinical research and practice. Biological psychiatry, 59(11), 990-996. https://doi.org/10.1016/j.biopsych.2005.09.014.

Kutiyski, Y., Krouwel, A., \& van Prooijen, J. W. (2019). Political extremism and distrust: Does radical political orientation predict political distrust and negative attitudes towards European integration? The Social Science Journal. https://doi.org/10.1016/j.soscij.2019.03.004.

Lakens, D. (2013). Calculating and reporting effect sizes to facilitate cumulative science: a practical primer for t-tests and ANOVAs. Frontiers in psychology, 4, 863. https://doi.org/10.3389/fpsyg.2013.00863.

Levitas, R., Pantazis, C., Fahmy, E., Gordon, D., Lloyd, E., \& Patsios, D. (2007). The multi-dimensional analysis of social exclusion. Bristol: University of Bristol.

Maner, J. K., DeWall, C. N., Baumeister, R. F., \& Schaller, M. (2007). Does social exclusion motivate interpersonal reconnection? Resolving the porcupine problem. Journal of Personality and Social Psychology, 92(1), 42. https://doi.org/10.1037/0022-3514.92.1.42.

Mayda, A. M. (2006). Who is against immigration? A cross-country investigation of individual attitudes toward immigrants. The review of Economics and Statistics, 88(3), 510-530. https://doi.org/10.1162/ rest.88.3.510.

Nakagawa, S., Johnson, P. C., \& Schielzeth, H. (2017). The coefficient of determination R 2 and intra-class correlation coefficient from generalized linear mixed-effects models revisited and expanded. Journal of the Royal Society Interface, 14(134), 20170213. https://doi.org/10.1098/rsif.2017.0213.

Ponce, A. (2017). Gender and anti-immigrant attitudes in Europe. Socius: Sociological Research for a Dynamic World, 3, 1-17. https://doi.org/10.1177/2378023117729970.

Pottie-Sherman, Y., \& Wilkes, R. (2017). Does size really matter? On the relationship between immigrant group size and anti-immigrant prejudice. International Migration Review, 51(1), 218-250. https://doi. org/10.1111/imre.12191.

Preacher, K. J., \& Selig, J. P. (2010). Monte Carlo method for assessing multilevel mediation: An interactive tool for creating confidence intervals for indirect effects in 1-1-1 multilevel models [Computer software].

Quillian, L. (1995). Prejudice as a response to perceived group threat: Population composition and antiimmigrant and racial prejudice in Europe. American sociological review. https://doi.org/10.2307/20962 96.

Rink, N., Phalet, K., \& Swyngedouw, M. (2008). The effects of immigrant population size, unemployment, and individual characteristics on voting for the Vlaams Blok in Flanders 1991-1999. European sociological review, 25(4), 411-424. https://doi.org/10.1093/esr/jen028.

Rockwood, N. J. (2017). Advancing the formulation and testing of multilevel mediation and moderated mediation models. Doctoral dissertation, The Ohio State University.

Roets, A., \& Van Hiel, A. (2011). Allport's prejudiced personality today: Need for closure as the motivated cognitive basis of prejudice. Current Directions in Psychological Science, 20(6), 349-354. https://doi. org/10.1177/0963721411424894.

Rotter, J. B. (1971). Generalized expectancies for interpersonal trust. American psychologist, $26(5), 443$. https://doi.org/10.1037/h0031464.

Rotter, J. B. (1980). Interpersonal trust, trustworthiness, and gullibility. American psychologist, $35(1), 1$. https://doi.org/10.1037/0003-066X.35.1.1. 
RStudio Team (2015). RStudio: Integrated Development for R. RStudio, Inc., Boston, MA URL http:// www.rstudio.com/.

Rustenbach, E. (2010). Sources of negative attitudes toward immigrants in Europe: A multi-level analysis. International migration review, 44(1), 53-77. https://doi.org/10.1111/j.1747-7379.2009.00798.x.

Satorra, A., \& Muthen, B. (1995). Complex sample data in structural equation modeling. Sociological methodology, 25(1), 267-316.

Scheve, K. F., \& Slaughter, M. J. (2001). Labor market competition and individual preferences over immigration policy. Review of Economics and Statistics, 83(1), 133-145. https://doi.org/10.1162/00346 5301750160108.

Scutella, R., Wilkins, R., \& Kostenko, W. (2009). Estimates of poverty and social exclusion in Australia: a multidimensional approach (No. wp2009n26). Melbourne Institute of Applied Economic and Social Research, The University of Melbourne.

Silver, H. (1994). Social exclusion and social solidarity: three paradigms. Int'l Labortory Review, 133, 531.

Silver, H. (1995). Reconceptualizing social disadvantage: Three paradigms of social exclusion (pp. 57-80). Social exclusion: Rhetoric, reality, responses.

Tajfel, H., \& Turner, J. C. (1986). The social identity theory of intergroup behavior. In S. Worchel \& W. G. Austin (Eds.), Psychology of intergroup relations (pp. 7-24). Chicago: Nelson-Hall.

Twenge, J. M., Baumeister, R. F., DeWall, C. N., Ciarocco, N. J., \& Bartels, J. M. (2007). Social exclusion decreases prosocial behavior. Journal of personality and social psychology, 92(1), 56. https://doi. org/10.1037/0022-3514.92.1.56.

Twenge, J. M., Baumeister, R. F., Tice, D. M., \& Stucke, T. S. (2001). If you can't join them, beat them: effects of social exclusion on aggressive behavior. Journal of personality and social psychology, 81(6), 1058. https://doi.org/10.1037//0022-3514.81.6.1058.

Twenge, J. M., Catanese, K. R., \& Baumeister, R. F. (2002). Social exclusion causes self-defeating behavior. Journal of personality and social psychology, 83(3), 606. https://doi.org/10.1037/0022-3514.83.3.606.

Uslaner, E. M. (2008). Trust as a moral value. In D. Castiglione, J. W. van Deth, \& G. Wolleb (Eds.), Handbook of social capital (pp. 101-121). Oxford: Oxford University Press.

Uslaner, E. M. (2002). The moral foundations of trust. Cambridge: Cambridge University Press.

Ward, P. R., Miller, E., Pearce, A. R., \& Meyer, S. B. (2016). Predictors and extent of institutional trust in government banks the media and religious organisations: evidence from cross-sectional surveys in six Asia-Pacific countries. PloS one. https://doi.org/10.1371/journal.pone.0164096.

Wilkes, R., Guppy, N., \& Farris, L. (2007). Right-wing parties and anti-foreigner sentiment in Europe. American Sociological Review, 72(5), 831-840.

Williams, K. D., \& Sommer, K. L. (1997). Social ostracism by coworkers: Does rejection lead to loafing or compensation? Personality and Social Psychology Bulletin, 23(7), 693-706. https://doi. org/10.1177/0146167297237003.

Publisher's Note Springer Nature remains neutral with regard to jurisdictional claims in published maps and institutional affiliations. 